\title{
A Comparative Study of Self-Esteem between Sports - Men and Women
}

\author{
Shashidhara ${ }^{1}$, Sukashant S. Patil ${ }^{2}$ \\ ${ }^{1}$ Research Scholar, University College of Physical Education, Bangalore university- Bangalore \\ ${ }^{2}$ Research Scholar, LNCPE Trivandrum-University of Kerala, India
}

\begin{abstract}
The purpose of the present study was to compare the level of Self esteem among sportsmen and sportswomen. To achieve the purpose of the study 100 sportsmen and 100 sportswomen were selected from different colleges under Karnatak University, Dharwad In the year of 2014-15. The Subjects age ranges from 18-28 years. The data for the study were collected by using questionnaire technique. The scores on self esteem were collected by administrating Rosenberg self esteem scale. This survey was taken by the investigator presence and Necessary instruction was given by him and there was no use of any motivational technique. It was clearly explained to the subjects that overall purpose of the study was to compare the self-esteem between sportsmen and sportswomen. However the subjects were made to respond as quickly as possible without any confusion. Statistical technique ' $t$ ' ratio was used to compare the self-esteem between selected groups. The results revealed that there was a significant difference found in sportsmen and sportswomen.
\end{abstract}

Keywords: Sportsmen, sportswomen and Self esteem

\section{Introduction}

Physical education is the most important factor of common education. It is the education through physical activities it means in physical education how much importance goes to physical factor; the same importance goes to psychological factors also. The aim of the education is overall development of human. The aim of the physical education is not out of common education it helps to overall development of child through physical activities.

Today sports are considered as international discipline as it develops international understanding and universal brotherhood. Sports develop national character and also it provides to fullest self expression to man and it is one of the fundamental needs. Human being is considered as an intellectual animal that wants to participate in physical activities to attain personal achieve growth and development and to maintain good health. It is natural is both quality and a child to participate in activities like running, jumping, throwing etc.

\section{Sports}

The word 'Sports' occasionally denotes either to a pleasant part time or somewhat hazardous recreation. Sports are psycho-social activity. Sports have a very important role in modern society. It is important to an individual, a group, a nation and indeed the world. The word sports have a popular appeal among people of all ages and both sexes, much of the attraction of sports comes from the wide variety of experience and feelings that result from participation of joy, anguish, success, failure, exhaustion pain relief and a feeling of belonging.

\section{Self Esteem}

Self-esteem reflects a person's overall subjective emotional evaluation of his or her own worth. It is a judgment of oneself as well as an attitude toward the self. Self-esteem encompasses beliefs and emotions such as triumph, despair, pride, and shame. Smith and Mackie (2007) defined it by saying "The self-concept is what we think about the self; self-esteem is the positive or negative evaluations of the self, as in how we feel about it. Self-esteem is attractive as a social psychological construct because researchers have conceptualized it as an influential predictor of certain outcomes, such as academic achievement, happiness, satisfaction in marriage and relationships and criminal behaviours. Self-esteem can apply specifically to a particular dimension or a global extent. Psychologists usually regard self-esteem as an enduring personality characteristic ("trait" self-esteem), though normal, short-term variations ("state" self-esteem) also exist. Synonyms or near-synonyms of selfesteem include: self-worth, self-regard, self-respect and selfintegration.

Purpose of the study: The main purpose of this study was to analyze the level of Self esteem between sportsmen and sportswomen.

Statement of the problem: To check whether any differences between sportsmen and sportswomen in the level of self esteem?

Hypothesis: There was no significant difference between the level of Self esteem in sportsmen and sportswomen.

\section{Limitations:}

- Can't control the environment/surrounding of the subjects.

- Non consideration of daily routine activities, training, and food habits of the subjects.

- Can't control of the psychological Status / condition of subjects.

- Family background of the subject was not considered.

- The response of the subject to the questionnaire might not be honest in all cases and this was recognized as a limitation. 


\section{International Journal of Science and Research (IJSR) \\ ISSN (Online): 2319-7064}

Index Copernicus Value (2013): 6.14 | Impact Factor (2015): 6.391

\section{Delimitation}

- In this study we selected the subject's from who participated in the level of inter collegiate and inter university competition.

- This study contains the age of a sportsman between 18-28 years.

\section{Methodology}

As discussed earlier the main purpose of the study was investigating the varying level of Self esteem between sportsmen and sportswomen. For this purposes the standardized "Self esteem" Questionnaire was administered. The selection of the subject and procedure followed by the collection of data and analysis used in this study are described in the following sections.

\section{Subjects}

For the study 100 sportsmen and 100 sportswomen who participated inter collegiate and inter university tournaments in different games were chosen.

\section{Tool}

Self-esteem is typically assessed using self-report inventories. One of the most widely used instruments, the RSES (Rosenberg, 1965) is a 10-item self-esteem scale scores that requires participants to indicate their level of agreement with a series of statements about themselves and it is generally considered as the standard against which other measures of self-esteem has compared. This questionnaire has four point rating scale, response ranging from strongly disagree to strongly agree.

\section{Administration of Test}

The standardised self esteem questionnaire was personally administered to the subjects by investigator. The researcher has briefly explained about the purpose of conducting the study. The sufficient time was given to the subjects to carefully read, understand the questions before making response, after those respondent sheets were collected immediately.

\section{Scoring}

The data were collected through the administration of the questionnaire, which is a test item with four choice for each item ranging from Strongly agree-1, agree-2, Disagree-3,
Strongly disagree-4. Some of the statement had reverse scoring to control the response bias. Items 2, 5, 6, 8, and 9 are reverse scored. Give "Strongly Disagree" 1 point, "Disagree" 2 points, "Agree" 3 points, and "Strongly Agree" 4 points. Sum scores for all ten items. Keep scores on a continuous scale. Higher scores indicate higher self-esteem.

To measure sports related self esteem of the sportsman's and sportswomen Questionnaire test (That is developed by Rosenberg, 1965) was introduced. Then each subject's composite score was found .Then that scores was analyzed according to scale. All 200 subjects were first of all provided to following self esteem questionnaire and they were asked to give their opinion strictly independent manner. It contains 10 items.

\section{Statistical Techniques}

The data that was collected from the subjects was treated statistically. To test the hypotheses data was analysed to independent sample t- test which will locate significant difference between pair of means. The level of significance was fixed at 0.05 .

\section{Analysis of the Data}

The significance of the difference between the means of sportsmen and sportswomen was found out. The date were analysed and dependent t test was used with 0.05 levels of confidence.

Table 1: Analysis of ' $T$ '- Ratio for the Self-Esteem among Sportsmen and Sportswomen.

\begin{tabular}{|c|c|c|c|c|c|c|c|}
\hline SL NO & Variable & Group & N & Mean & SD & Df & ' $\mathrm{t}$ ' \\
\hline \multirow{3}{*}{1} & & sportsmen & 100 & 19.98 & 3.45 & & \\
\cline { 3 - 7 } & Self & sportswomen & 100 & 18.49 & 2.98 & 198 & $2.83 *$ \\
\hline
\end{tabular}

Level of Significance 0.05 (df of 198 is 1.98)

The table 1 shows that the mean values of sportsmen and sportswomen on the level of self esteem were 19.98 and 18.49 respectively. The obtained ' $t$ 'ratio was $2.83 *$ since the obtained calculated value was greater than table value of 1.98 for significance at 0.05 level with 198 degrees of freedom it was found to be statistically significant.. The results of the study showed that there was a significant difference between sportsmen and sportswomen in the level of self esteem. Therefore the null hypothesis is rejected.

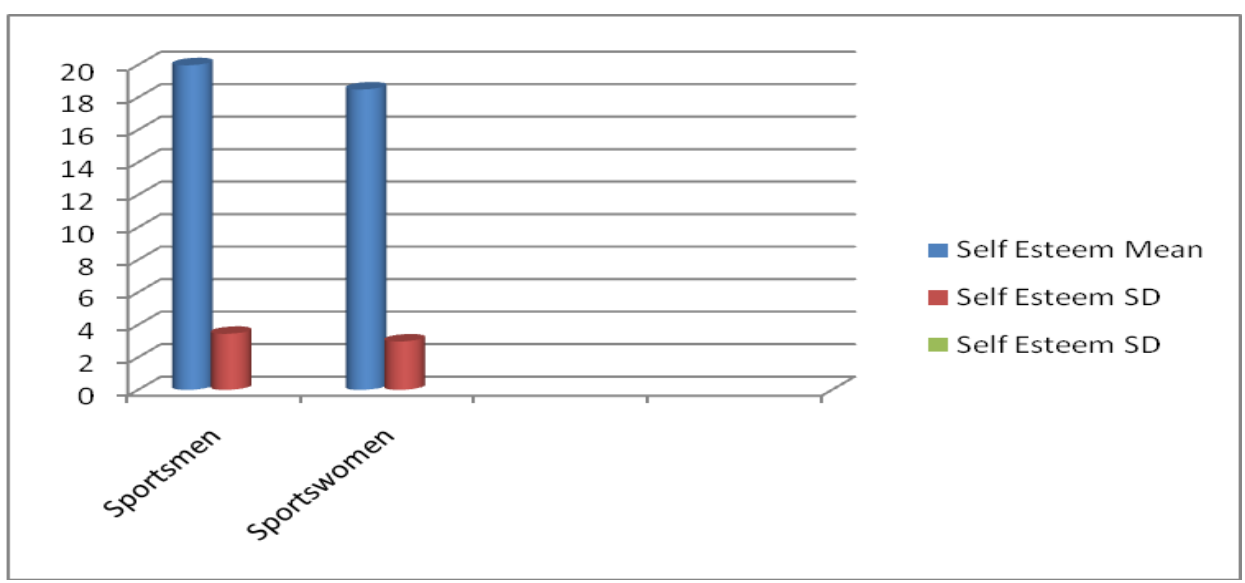

Figure: A graphical representation shows the mean and SD of "Self esteem" between sportsmen and sportswomen.

Volume 5 Issue 6, June 2016 www.ijsr.net 


\section{Results}

From the statistical analysis it was concluded that the sportsmen were having higher self esteem level than sportswomen.

\section{Discussion}

One of the major objectives of the present study was to assess the Self Esteem between sportsmen and sportswomen. As anticipated players mainly sportsmen were having significantly higher Self Esteem level than sportswomen. Gender pattern have often been found within self-esteem. Studies during the 1970s and 1980s in the united states regularly found girls self concept more vulnerable during early adolescents not after (Rosenberg 1973). But sportsmen self esteem has highly dependent on their sense of mastery, much spectators support, encourage by family and society and Huge opportunities (competition and job) while girls has more dependent on relationships, especially parental support (brutsart 1990). Less chances, lack of support and only few no of mega competitions might be affect on this psychological factor. For the high level Consistent performance every players and coaches must give a greater preference to this psychological factor.

\section{Conclusion}

Concluded based on the findings of this study that sportsmen showed higher Self Esteem as compared to sportswomen. The study found that there were significant differences between sportsmen and sportswomen with respect to Self Esteem .From the study it may be concluded that sportsmen were more level of self esteem compare to sportswomen.

\section{References}

[1] Pervin, 1989). Self Esteem ( SE) is a personal judgment of worthiness

[2] Podesta (2001) Self Esteem is appreciating one's own worth and importance and having the character to be accountable for oneself and to act responsibly towards others

[3] Baumeister, RF, Smart, L, Boden, JM (1997) Relation of Threatened Egotism to Violence and Aggression: The Dark Side of High Self Esteem, Psychological Review 103, pp. 5-33.

[4] S Mercer (2008). From the Top Down: Self Esteem and Self-Evaluation, Cognition and Emotion 15, pp. 615-631.

[5] Rosenberg (1979) self-concept as a descriptive construct.

[6] Branden, N. (1969). The psychology of self-esteem. New York: Bantam. Branden, N. (2001). The psychology of self-esteem: a revolutionary approach to selfunderstanding that launched a new era in modern psychology. San Francisco: JosseyBass, 2001. 